\title{
Analisis Teknik Permainan Bagian Pertama Konserto Oboe dalam C Mayor karya Wolfgang Amadeus Mozart (1756- 1791)
}

\author{
Afdhal Zikri Zz \\ Hoboist profesional, Alumni Jurusan Musik, FSP ISI Yogyakarta \\ Telp. 085643501767; e-mail: ericbardawi@gmail.com.
}

\begin{abstract}
Oboe playing techniques within Mozart's Oboe Concerto in C Major, K. 314, are having a quite high difficulty level. Its techniques especially fingering and breathing are not easily achieved except through long-term discipline practices. Due to its high-level difficulties, this work is often used as main materials for an international well-known orchestra audition. This work was performed by the author in his undergraduate final exam at Music Department, ISI Yogyakarta. The analysis of this work was aimed at understanding its musical style as well as its applied oboe techniques for further interpretation. Through this analysis, the author looks at a playing approach by trying several musicological as well as technical possibilities for his interpretation.
\end{abstract}

Keywords: Oboe playing technique; Concerto; interpretation

\begin{abstract}
Abstrak
Teknik permainan oboe yang terkandung dalam Konserto C Major Oboe karya Mozart memiliki tingkat kesulitan yang tinggi. Teknik-tekniknya, khususnya fingering dan pernapasan tidaklah mudah untuk dicapai kecuali melalui latihan-latihan yang penuh disiplin dalam waktu yang tidak sebentar. Dengan tingkat kesulitan yang tinggi karya ini sering dipakai untuk audisi untuk orkestra yang berkelas internasional. Karya ini dimainkan oleh penulis saat menyelesaikan studi Sarjana di Jurusan Musik ISI Yogyakarta. Melalui penelitian ini penulis mencari pendekatan tekknik permainan dengan mencoba berbagai berbagai kemungkinan musikologis maupun teknis dalam menginterpretasikan karya ini.
\end{abstract}

Kata Kunci: Teknik permainan oboe; Konserto; interpretasi

\section{Pengantar}

Seorang pemain oboe untuk dapat membawakan lagu dengan baik tidak hanya cukup mengandalkan segi motorik saja, diperlukan pemahaman terhadap Ilustrasi musik serta mengetahui karakter istimewa dari tiap bagian dalam komposisi yang akan dibawakan. Kegiatan ini akan sangat membantu pemain dalam menginter-pretasikan part yang akan dimainkan. Selain itu, pemain juga harus mempunyai wawasan pengetahuan khususnya informasi yang berhubungan dengan komposisi (sejarah komposer, kapan karya itu dibuat serta ide musikal yang ada dalam komposer dan karyanya), serta yang tak kalah penting juga adalah pengalaman dalam bermain musik. Interpretasi musik juga dapat diartikan memainkan atau menerjemahkan suatu komposisi dengan 
penghayatan yang penuh rasa tanggung jawab dalam menyesuaikan maksud kehendak dari komposer tersebut.

Begitu pula dalam bermain oboe, seorang pemain oboe yang serius tidak sekedar meniupnya saja, setiap kegiatan musikalnya oboe hendaknya dilandasi kemampuan memberikan interpretasi de- ngan benar. Melakukan kegiatan musikal erat hubungannya dengan tingkat pen- dalaman seseorang terhadap karya musik yang akan dimainkan dengan kata lain faktor interpretasi sangat mempengaruhi pen- jiwaaan serta pengungkapan seorang terha- dap karya musik. Dalam musik, intepretasi berkaitan dengan teknik bermain. Pemahaman interpretasi akan dikaji melalui ekpresi yang tertera pada partitur.

Teori tentang konserto dibahas secara komprehensif oleh Huching (1980: 628-639) mulai dari tinjauan hsitoris sejak awal Barok hingga perkembangannya pada periode Moderen. Di antaranya disebutkan bahwa Oboe digunakan tidak semata-mata sebagai ciri khas orkestrasi Konserto awal Mozart namun juga sebagai solis sebagaimana halnya instrimen tiup kayu yang lain, seperti Klarinet, Fagot, dan Flute. Sejarah tentang instrumen oboe merupakan salah satu bahasan dalam pustaka-pustaka umum tentang musik seperti terdapat dalam Goosens dan Roxburgh (1977). Sementara teknik-teknik dasar bermain oboe dibahas dalam pustaka khusus tentang tiup kayu (Sucier, 1981), detil teknik-teknik yang dipergunakan dalam bermain Oboe dibahas oleh Rothwell dalam bukunya Oboe Technique (London, 1982).

Di dalam Konserto oboe C Mayor K.V. 314 karya Mozart, terdapat beberapa teknik yang digunakan pada tiap bagiannya. Pada setiap teknik mempunyai kesulitan masing-masing dan mempunyai solusi untuk mengatasi masalah tersebut. Lagu "Konserto Oboe In C Major" merupakan salah satu karya dari Wolfgang Amadeus Mozart yang diciptakan pada tahun 1977. Untuk seorang solis bernama Giussepe Ferlendis dari
Bergamo. Karya ini dimainkan dengan solo oboe dan iringan Orkestra (Piano). Lagu ini terdiri dari 3 bagian bagian pertama bertempo Allegro Aperto, bagian ke dua Adagio ma non troppo, dan bagian ketiga bertempo Allegretto (rondo). Pembahsan dalam studi ini dibatasi pada bagian pertama saja.

\section{Pembahasan}

Guna mengetahui teknik yang terkandung pada bagian pertama karya Wolfgang Amadeus Mozart ini, yaitu Konserto Oboe dalam C Mayor, K.V. 314, kajian telah dilakukan melalui beberapa langkah. Sehubungan dengan itu pem-bahasan ini meliputi analisis struktur lagu yang kemudian dilanjutkan dengan teknik-teknik permainan yang terdapat dalam lagu tersebut, dan analisis keterkaitan antara pengolahan teknikteknik tersebut dengan interpretasi permainan oboe. Analisa teknik permainan dan interpretasi oboe pada karya ini akan memberikan kontribusi yang dapat membantu para pemain oboe agar mengetahui teknik permainan dan bagai-mana cara memainkan lagu dengan benar serta dapat menginterpretasikan maksud yang terkandung didalam lagu tersebut.

\section{Analisis Bentuk Musik}

Karya Mozart, Konserto Oboe dalam C Mayor, K.V. 314 ini menggunakan struktur standar bentuk komposisi jaman klasik, yaitu yaitu bentuk sonata allegro bagian pertama. Secara keseluruhan Konserto ini memiliki tiga bagian. Bagian pertama dengan tempo allegro aperto, bagian kedua adagio ma non troppo dan bagian ketiga menggunakan bentuk rondo dengan tempo allegretto. Analisis teknik permainan bagian pertama pada karya ini terdiri dari 188 birama.

Secara umum bentuk dari gerakan gerakan pertama Konserto ini dibagi menjadi tiga bagian yaitu Eksposisi (tema I dan II), pengembangan (development), dan Rekapitulasi. Sabagaimana lazimnya Konserto jaman Klasik, karya ini adalah bentuk sonata 
dengan dua eksposisi. Eksposisi pertama dimainkan oleh Orkestra, yang biasa disebut Introduksi, dan tema kedua dimainkan oleh solo oboe sementara bagian orkestra tersaji sebagai kontras dari melodinya.

a. Eksposisi (tema):

Bagian eksposisi terdiri dari introduksi orkestra (birama 1-31). Untuk selanjutnya disusul dengan bagian solo oboe sementara orkes mengiringi atau sebagai counter dari Oboe. Berikut adalah melodi yang dibawakan oleh orkestra sebagai introduksi.

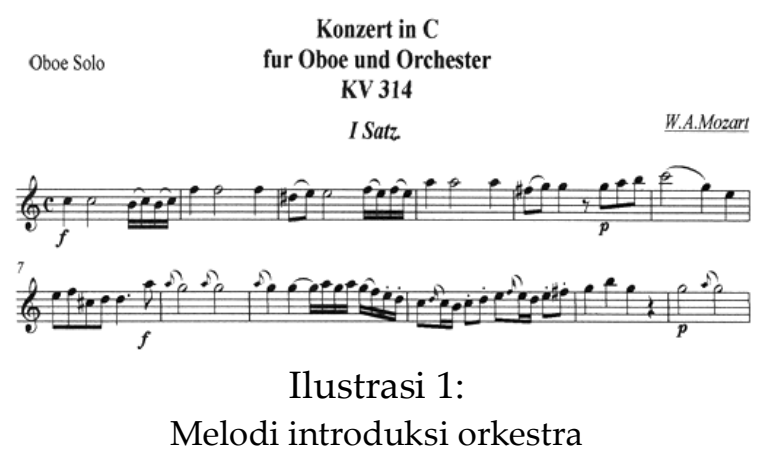

Untuk selanjutnya Tema I yang dibawakan oleh Oboe terdapat pada birama 33 hingga 47, sebagai berikut:

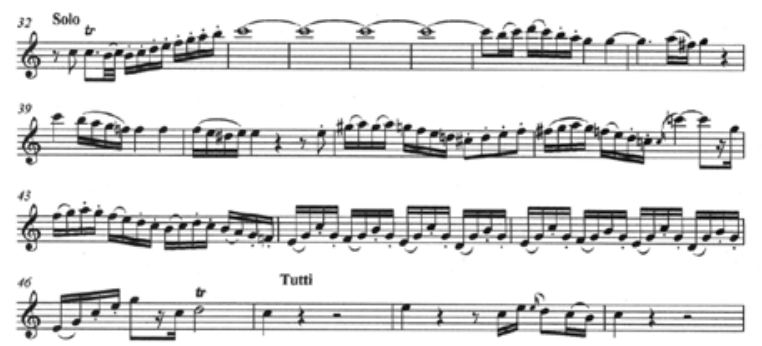

Ilustrasi 2.

Tema 1

Tema 2: birama 50-58

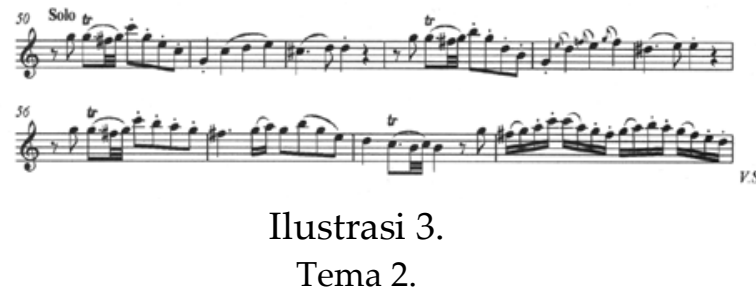

b. Development (pengembangan): birama 106-115, Tema I dimainkan dengan tangga nada yang berbeda dan dikembangkan dengan cara sekuen

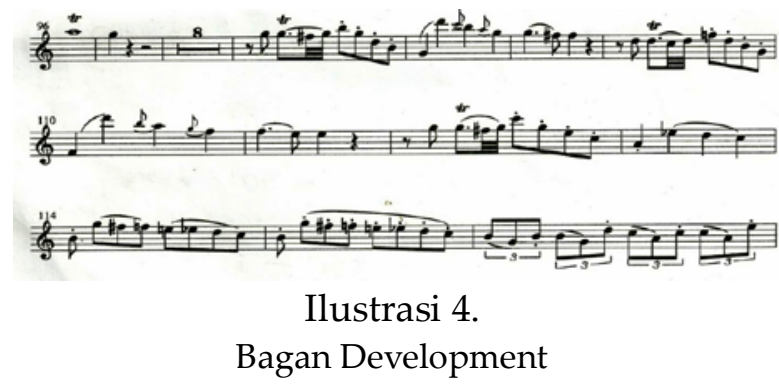

c. Retransisi : birama 116 -119

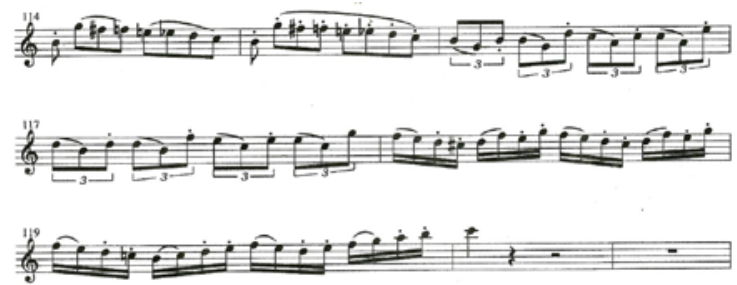

Ilustrasi 5:

Bagian re-Transisi menjelang Rekapitulasi

d. Rekapitulasi: 120-136, mengambil pengembangan di eksposisi secara singkat, dan pada birama 120 diawali dengan tutti yang dimainkan Orkestra, dan solo masuk di birama 122 .

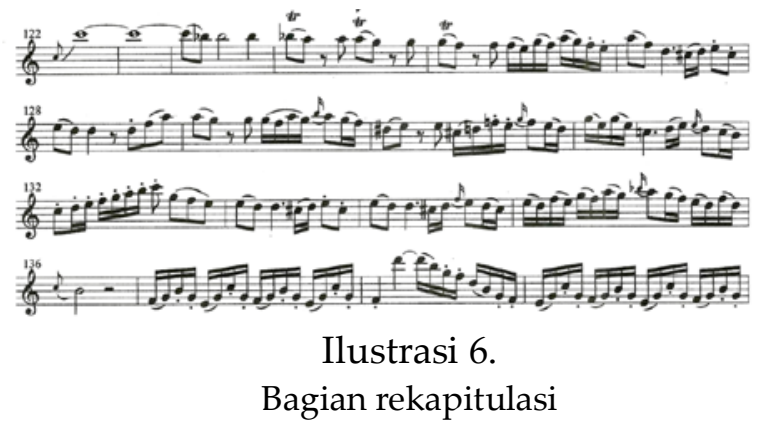

e. Codetta: pada birama 175-178, yang dimainkan oleh orkestra sebelum solo memasuki cadenza, yaitu sebuah bagian solo untuk menunjukkan virtuositas atau tingkat kemampuan solis dalam, yang berada akhir bagian, ada yang ditulis oleh komposer dan ada juga yang dibuat oleh solis itu sendiri.

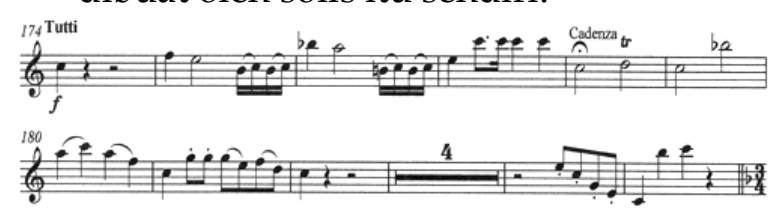




\section{Ilustrasi 7.}

Bagian Codetta menjelang Cadenza

\section{Teknik Pernapasan}

Pernafasan adalah teknik utama yang sangat penting untuk dapat menguasai teknik-teknik dalam instrumen tiup. Sikap tubuh seorang pemain oboe saat meniup instrumen dapat mencerminkan sistem Pernafasan yang sedang digunakan. Ada empat sistem Pernafasan yang digunakan oleh para pemain tiup, yaitu:

\section{a. Pernafasan Bahu (Claviculair)}

Pada saat mengambil nafas, hanya bagian atas paru-paru yang terisi udara, sehingga mendesak bahu menjadi terangkat ke atas. Pernafasan ini sangat dangkal, tidak tahan lama, dan sikap tubuh pada waktu meniup menjadi kurang indah.

\section{b. Pernafasan Dada (Costal)}

Pada saat mengambil nafas, seluruh paru-paru bagian tengah terisi udara, sehingga rongga dada membusung kedepan. Kelemahan bernapas dengan sistem ini, yaitu paru-paru cepat menjadi lelah dalam menahan udara, maka suara yang dihasilkan tidak stabil, karena udara yang dikeluarkan kurang dapat diatur, sehingga pertengahan frase udara yang tersedia sudah habis dan pemain terpaksa mengambil nafas lagi.

\section{c. Pernafasan Perut (Abdominal)}

Pada saat mengambil nafas, menimbulkan gejala perut bagian depan mengembang. Sistem ini sudah lebih baik dari pada kedua sistem pernafasan di atas, namun belum seluruh paru-paru dapat dimanfaatkan untuk menampung udara. Jadi sistem ini juga menguntungkan bagi Pemain.

Paru-paru yang belum dimanfaatkan untuk menampung udara dengan penuh, akan sulit memainkan frase yang panjang. Persediaan udara sudah habis sebelum frase panjang selesai dimainkan. d. Pernafasan Diafragma (sekat rongga badan)

Pada saat mengambil nafas, udara masuk kedalam seluruh rongga paru-paru. Rongga- rongga diantara tulang-tulang iga hingga sekat rongga badan antara dada dan perut (diafragma) dikembangkan. Pada saat itu diafragma terdorong ke bawah, sehingga sisi-sisi tubuh bagian depan, belakang, samping kiri dan kanan mengembang ke luar. Pada saat mengeluarkan nafas, udara keluar untuk memproduksi tiupan. Diaphragma menekan paru-paru dari bawah, serta dibantu oleh otot-otot sisi tubuh.

Pernafasan yang banyak digunakan oleh pemain tiup adalah sistem pernafasan secara alamiah yaitu dengan menggunakan sekat rongga badan (diaphragma). Beberapa keuntungan pemain tiup yang menggunakan sistem pernafasan sekat rongga badan adalah:

- Paru-paru dapat terisi udara dengan penuh. Dengan demikian dapat memenuhi kebutuhan pemain tiup, karena pada saat akan memproduksi tiupan pemain membutuhkan persediaan udara yang relatif banyak di dalam paru-parunya.

- Pemain tiup dapat mengatur keluarnya udara sedikit demi sedikit, dengan menekan sekat rongga badan ke atas secara perlahan-lahan. Hal ini berarti bahwa udara yang dikeluarkan untuk memproduksi tiupan akan lebih panjang, sehingga pemain dapat memainkan satu kalimat lagu yang panjang dalam satu tarikan nafas.

- Dengan mempertahankan otot-otot perut dan sisi-sisi tubuh pada saat mengeluarkan nafas, maka udara dari pemain akan terus terjaga baik dalam dinamik keras maupun lembut.

- Pengeluaran nafas yang dapat diatur oleh pemain dengan mendorong 
sekat rongga badan atas, maka akan menghasilkan intonasi yang stabil.

- Sikap tubuh waktu bermain akan lebih indah, karena dada, bahu, dan temggorokan lebih rileks.

\section{Tekik Ambasir}

Dalam bahasa Perancis, ambasir (embochur) berarti "meletakkan", atau bisa juga merupakan kata benda yang berarti "mulut". Akan tetapi kata Ambasir yang digunakan oleh seluruh pemain tiup adalah kata yang digunakan untuk menggambarkan posisi bibir yang diperlukan untuk memainkan instrumen mereka. Kata ambasir di sini juga menyiratkan perkembangan otot di sekitar reed.

\section{a. Fungsi Ambasir}

Fungsi otot ambasir adalah untuk mengatur bukaan reed dan juga menentukan volume aliran udara yang melaluinya, kecepatan serta tekanan udara yang melaluinya. Aliran udara dalam volume tertentu dapat mengalir melalui lubang kecil dengan lebih cepat, karena tekanan udara lebih besar daripada volume yang sama, namun mengalir pada lubang yang lebih besar. Untuk lebih jelasnya, kita dapat melakukan sebuah test yang mudah ini tanpa menggunakan oboe. Ambil napas dalam-dalam, bentuk bibir anda seperti akan mengucapkan kata "Ah", letakkan jari tangan anda tepat di depan bibir. Kemudian hembuskan napas melalui mulut secara perlahan, statis dan terus menerus tanpa mengubah volume dan tekanan udaranya. Lalu, persempit bukaan bibir seperti mengucapkan "Oo", maka jari tangan akan dapat merasakan perbedaan kecepatan dan tekanan udara yang dihasilkannya bukaan bibir yang lebih sempit daripada yang lebar. Setelah itu naikkan tekanan aliran udara, kontraksikan otot ambasir untuk mengurangi/mengecilkan bukaan reed. Un- tuk mengurangi tekanan aliran udara, istirahatkan otot ambasir untuk membuat reed terbuka.

Jelasnya, tekanan aliran udara akan berubah jika volume udara yang berubahubah ditiupkan ke dalam lubang sama. Lakukan tes berikut ini untuk lebih memahami penjelasan di atas. Buka mulut dengan posisi bibir membentuk kata "Oo", letakkan jari kita tepat di depan mulut tanpa menyentuhnya, lalu hembuskan napas dengan kecepatan yang bervariasi, cepat dan lambat, maka jari akan merasakan perubahan tekanan aliran udara sebagaimana volumenya yang naik dan turun. Yang harus selalu diingat adalah, bahwa otot pernapasan harus membantu otot ambasir, yaitu menghasilkan volume udara yang diperlukan dalam keadaan tersebut. Nada yang indah dan terkontrol dengan baik hanya dapat dicapai jika aliran udara diatur oleh koordinasi yang baik antara otot pernapasan dan otot ambasir.

b. Pembentukan/ Formasi ambasir.

Formasi ambasir tergantung kondisi fisik pemain sendiri. Untuk meyakinkan diri kita bahwa suatu bentuk ambasir seseorang, tidak perlu mirip dengan orang lain. Kita harus menyadari adanya perbedaan bentuk/susunan rahang, gigi, dan bibir, begitu pula bentuk ambasir-nya. Tetapi, setiap ambasir yang baik, bagaimanapun terbentuknya, seharusnya dapat menghasilkan nada yang indah, kontrol yang akurat dan sensitif terhadap dinamik dan intonasi.

Ada beberapa poin yang berkaitan dengan pembentukan ambasir, ketika mulai bermain oboe, otot ambasir kita belum terbentuk. Oleh karena itu, harap diingat bahwa sebelum otot ambasir terbentuk dengan baik, maka otot tersebut akan terasa kaku dan tidak nyaman, sebagaimana otot-otot lain bila terlalu sering digunakan daripada sebelumnya, meskipun rahang, gigi, bibir dan sebagainya berada dalam posisi yang benar, 
ambasir kita mungkin merasa kencang, terlalu mencengkeram sehingga terasa tidak nyaman.

Pada awalnya kita tidak dapat menentukan otot mana yang bekerja, dan sangat mungkin untuk mengembangkan teknik yang salah. Karena kesalahan teknis pada awal latihan akan sulit dibenahi di kemudian hari, maka disarankan pada saat awal latihan harus didampingi oleh seorang guru atau instruktur yang baik yang akan membantu kita mendapatkan ambasir secara alamiah, hal itu harus ditentukan secara mendetil oleh diri anda sendiri. Dengan cara ini kita akan dapat menghindari pembentukan otot yang salah dan kebiasan buruk. Berbeda sekolah, menganjurkan metode pengontrolan yang berbeda. Perbeedaan tersebut meliputi penggunaan otot tertentu, jenis reed, posisi rahang, gigi, bibir, lidah, dan sebagainya. Namun di sini kita tidak akan membahas pro dan kontra dari perbedaan cara bermain tersebut. Dalam hal apapun, suatu prosedur atau metode mungkin saja tidak tepat bila diterapkan pada suatu individu. Sebagaimana yang dijelaskan sebelumnya, ambasir merupakan hal yang bersifat individu. Suatu metode mungkin akan tepat diterapkan pada seseorang, namun belum tentu tepat bila diterapkan pada orang lain. Di sini akan dijelaskan tipe umum ambasir.

Ambasir pada oboe disebut ambasir fleksibel. Untuk membentuk tipe ambasir ini, rahang bagian atas dan bawah, bibir atas dan bawah tidak mengatup dengan terlalu rapat. Bentuk bibir ini seolah menjadi bantalan otot yang fleksibel bagi reed, menggenggam dengan erat tetapi tidak kaku, tegas sekaligus lembut. Kondisi ini memungkinkan aliran udara yang dihembuskan mengalir dengan bebas melaluinya dan bukaan reed dapat disesuaikan dengan mudah dan teliti. Jangan pernah menjepit reed terlalu kencang diantara bibir dan gigi dan memaksakan aliran napas melaluinya dengan otot tenggorokan. Jika aliran udara yang mengalir bebas melalui bagian dasar dada, volume udara dihasilkan oleh otot perut, lalu melewati tenggorokan, reed, kemudian turun ke oboe, dikontrol oleh ambasir yang tegas namun lembut dan tidak kaku. Dengan metode ini tidak akan merasakan perasaan kencang dan kaku pada otot tenggorokan anda.

Jika pemain pemula, kemungkinan akan merasa sangat sulit untuk merilekskan otot ambasir dan tenggorokan, dan akan cenderung menjepit reed dengan kencang, kadang bahkan menutupnya sehingga tidak ada suara yang keluar. semakin keras kita mencoba untuk rileks, semakin tegang otot ambasir. Hal ini dikarenakan kita terlalu menyadari dan berkonsentrasi pada satu bagian tertentu dari tubuh. Cara yang baik untuk membuatnya rileks adalah dengan membuatnya kencang di satu bagian tertentu, dan karena dinding otot perut harus benar-benar kencang ketika sedang memainkan instrumen, cobalah untuk mengkontraksikan otot tersebut secara sadar, rasakan otot itu mengeras dan melunak pada saat kita berdiri tegak, dan menarik ke dalam otot perut bagian bawah, ketika kita menaikkan tulang dada. Harus diingat bahwa lubang reed sangat kecil, dan otot ambasir harus memegangnya dengan cukup erat untuk memungkinkan tekanan udara atau napas untuk menggetarkan reed.

c. Petunjuk umum untuk ambasir fleksibel

Guna mendapatkan hasil yang maksimal maka perlu memperhatikan petunjuk umum untuk ambasir yang fleksibel, sebagai berikut:

1) Rahang bagian bawah harus didorong sedikit kebawah dan kebelakang, ada sedikit jeda diantara gigi. Bibir harus tetap kencang pada berlatih.

2) Bibir harus menutupi gigi dan ditarik ke dalam seperti diikat dengan karet di bagian tengah, membentuk bantalan otot 
yang kenyal untuk memegang dan mengontrol reed. Reed jangan sampai bersentuhan secara langsung dengan gigi.

3) Otot di sekeliling bibir harus kencang, namun tidak kaku.

4) Jangan menjepit reed terlalu kencang diantara bibir, tapi juga jangan membiarkan ada udara yang keluar di sekeliling reed, juga jangan sampai ada tonjolan udara di manapun. Tonjolan ini biasanya terjadi di antara gigi dan bibir atau di pipi. Adanya tonjolan udara ini menandakan kurangnya kontrol otot yang baik oleh bibir yang mengelilingi reed. Hal ini akan mempengaruhi nada, menyebabkan kontrol yang buruk dengan membuang tekanan udara dan mengganggu ambasir. Berlatihlah di depan cermin, jika kita melihat atau merasakan tonjolan udara terbentuk, berhentilah bermain lalu mulai lagi dengan ambasir yang baru. Jika kita merasa kesalahan ini susah diatasi, coba gunakan reed yang lebih lembut, dan hentikan latihan jika merasa otot ambasir sudah lelah.

5) Belajarlah untuk merasakan jumlah yang tepat seberapa dalam reed masuk ke dalam mulut, dan tentukan dengan kualitas suara yang dihasilkan. Reed di dalam mulut seberapa bagian yang tertutup oleh bibir, harus bervariasi berdasarkan ambasir dan jenis reed yang digunakan, dan ini juga harus ditentukan dengan perasaan untuk mengontrol dinamik dan intonasi. kesimpulannya semakin ambasir terkontraksi, semakin banyak bagian reed yang harus tertutup oleh bibir agar bibir dapat menahan reed dengan erat. Selanjutnya bahwa perubahan posisi reed di dalam mulut adalah hal yang penting, dan jangan menarik oboe menjauh dari ambasir atau mendorongnya terlalu dekat ketika sedang bermain, hal ini akan merubah posisi reed di dalam mulut. Selalu pegang instrumen anda dengan mata pada posisi yang normal.
Posisi oboe ketika dimainkan merupakan hal yang penting untuk membentuk format ambasir yang tepat. Sebagai aturan umum, tidak boleh ada tekanan yang tidak merata pada kedua bagian reed, karena ini akan mempengaruhi vibrasi dan sehingga menyebabkan resistensiterhadap kolom udara yang mengalir melalui instrumen. Oleh karena itu, sebagai aturan yang umum, salah satu bibir tidak boleh lebih menonjol keluar daripada bibir yang lain. Dalam banyak tipe ambasir, formasi gigi dan atau yang sebanding dengan pendeknya bibir atas, maka penting bagi rahang bawah, dan juga bibir bawah untuk sedikit menjorok ke depan agar sesuai dengan bibir atas. Namun menurut pengalaman solis oboe dunia, hal tersebut tidak penting untuk dilakukan. Sebagai panduan, sudut rata-rata memegang oboe adalah 45 derajat dari tubuh. Tapi kita harus menentukan sendiri berapa derajat sudutnya agar ambasir terasa nyaman dan benar.

Jika posisi oboe terlalu lebar dari badan, dan kita mengangkat oboe terlalu tinggi tetapi posisi kepala kebawah, akan membuat reed menjauh dari rahang bawah dan bantalan bibir bawah, yang menyebabkan bibir atas menekan terlalu keras. Hal ini akan mengakibatkan pitch yang flat, terutama untuk not bagian atas, dan bunyi yang mati. Jadi jagalah dagu dan leher untuk tetap tegak lurus.

Tetapi jika sudut yang diambil terlalu sempit, maka akan cenderung menekankan reed pada bibir bawah dan membuat bibir atas terlalu meregang untuk menyesuaikan pengontrolan. Hal ini akan mengakibatkan pitch yang terlalu tajam, terutama untuk nada-nada bagian atas dan suara yang berat.

Berlatih di depan cermin akan sangat membantu untuk mendapatkan postur tubuh yang baik dan benar. Nanti, dengan sendirinya kita akan dapat merasakan apakah postur dan posisi tubuh kita sudah benar dengan mendengarkan kualitas suara yang dihasilkan. 


\section{Dinamik}

Intonasi yang baik sangat vital bagi semua instrumen, tapi karena kualitas alamiah suara oboe itu sangat terkonsentrasi dan jelas, maka intonasi yang tidak sempurna akan terdengar menyakitkan, jadi kita harus berhati-hati. Permainan yang baik tergantung pada kemampuan telinga untuk menentukan ketepatan intonasi pada masing-masing nada, dan juga pada kemampuan mengontrol otot yang diperlukan untuk menentukan pitchnya (umumnya nada A $=440$ ).

Beberapa pemain terlahir dengan musikalitas telinga yang baik, namun ada juga yang tidak seberuntung itu, sehingga satu-satunya jalan adalah konsentrasi dan membiasakan telinga untuk peka dan kritis. Selalu dengarkan sendiri dengan kritis penuh perhatian, karena meniup tidak tepat, bisa menjadi kebiasaan yang tanpa disadari. berlatihlah tangga nada dan not-not panjang tanpa diberi Vibrasi. Selalu dengarkan not yang akan anda mainkan sebelum benarbenar memainkannya, lama kelamaan akan menjadi otomatis, bahkan sewaktu melakukan sight-reading (langsung membaca dan memainkan partitur tanpa dipelajari sebelumnya).

Sebagaimana telah dijelaskan sebelumnya, kontrol intonasi dan dinamik dicapai dengan sedikit perubahan volume dan tekanan aliran udara, dan perubahan ini diatur oleh kerjasama antara otot ambasir dan otot pernapasan.

Poin berikut ini merupakan poin yang bersifat umum, dan seperti yang telah dijelaskan sebelumnya, dan dapat diterapkan pada segala macam situasi dan pada semua jenis ambasir. Hal berikut ini merupakan metode yang banyak digunakan oleh pemain untuk menemukan tujuan utama mereka dengan mudah.

Dinamik adalah simbol musik yang menerangkan tentang keras lembutnya suara. Dinamik yang digunakan dalam lagu
Konserto C mayor Mozart adalah piano, forte, fortepiano.

Piano adalah dinamik lembut, dimainkan dengan intensitas nada yang pelan. Dinamik piano dalm konserto ini biasanya adalah nada panjang yang disertai dengan crescendo, yaitu terdapat pada birama 122:

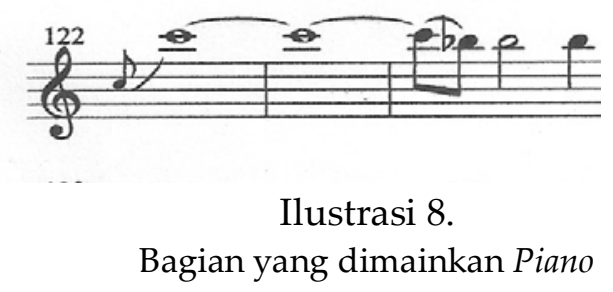

Pada birama ini, dinamik nya tidak ditulis di part, tetapi berasal dari cara kita menginterpretasi lagunya, dan beberapa referensi dari mp3 dan video-video solis di dunia.

Cara memainkan piano ialah dengan mengambil nafas yang banyak, ambasir relaks dam diusahakan tidak menggunakan lidah hanya udara saja, seperti mengucapkan kata $h u$ bukan $t u$, setelah itu udara dikeluarkan dengan sedikit demi sedikit dan rata, dan mendapat dorongan nafas dan diafragma ayang kuat agar suara yang dihasilkan lembut, dan perut ikut mengencang untuk mempertahankan nafas diafragma. Cara melatih dinamik piano adalah latian nada panjang sebanyak 4 ketuk pada tiap tiap nada dengan cara diatas, dengan tempo lambat (maksimal 70), diulangi terus sampai bibir kuat serta warna suara menjadi halus dan indah.

Forte adalah keras, dimainkan dengan intensitas nada yang keras, terdapat pada birama 37:

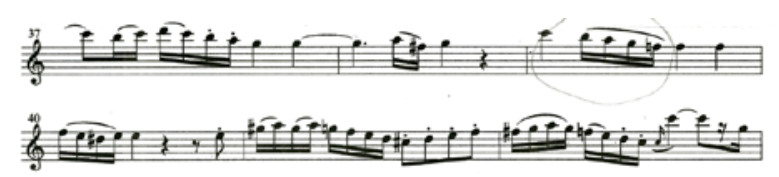

Ilustrasi 9.

Bagian dengan dinamik Forte. 
Pada birama ini juga dinamik tidak ditulis di part-nya, karena pada birama sebelumnya terjadi crescendo dan puncaknya ada pada birama 37.

Cara memainkan forte hampir sama dengan piano, yaitu dengan mengambil nafas yang banyak, tetapi bedanya ini menggunakan lidah, dan dibantu dengan suara tiupan dari mulut agar menimbulkan resonansi untuk sonoritas, dan dengan hentakkan udara yang dikeluarkan dengan kapasitas banyak, mendapat dorongan nafas dan diafragma agar suara keras dan stabil. Forte bisa dilatih dengan latian nada panjang selama 4 ketuk dalam tempo lambat, hasil bunyi forte dipertahankankan agar stabil dan diulang begitu seterusnya sampai bibir kuat serta warna suara menjadi halus.

Forte-piano adalah perpaduan dinamik antara piano dan forte, cara dengan teknik yang sama juga tetapi biasanya nada forte yang dihasilkan hanya pada ketukan pertama selanjut langsung tiba tiba (subito) menjadi piano. Dinamik fortepiano terdapat pada birama 80 dan 82 :

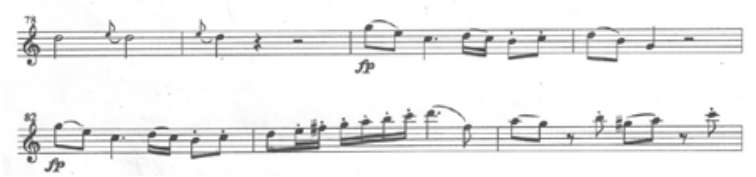

Ilustrasi 10.

Forte-piano

Crescendo adalah dinamik yang secara bertahap meningkat, dari lembut menjadi keras. Secara fungsi crescendo untuk membangun suasana pada birama 33:

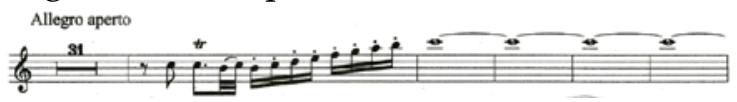

Ilustrasi 11:

Bagian yang dimainkan crescendo

Pada birama ini, tanda dinamik crescendo tidak tertulis di part, tapi crescendo muncul dari interpretasi dari pemain itu sendiri, yang didapat dari beberapa referensi video dari solis oboe yang sudah terkenal di dunia.
Pada saat melakukan crescendo bunyi yang sebelumnya piano sedikit demi sedikit ditingkatkan menjadi lebih keras dari sebelumna, untuk membuat crescendo, Bernapaslah dengan lebih cepat, tingkatkan volume aliran udara. Udara harus mengalir dengan bebas, naik melalui dada. Jangan menggunakan otot tenggorokan. Dan reed harus bisa terbuka secara teratur untuk bergetar dengan lebih bebas. Rilekskan bibir yang mengelilinginya. Kecenderungan untuk sharp selama crescendo mungkin dikarenakan ambasir yang tidak cukup rileks dan/atau terlalu banyak bagian reed yang tertutup oleh bibir.

\section{Intonasi}

Tone quality adalah kualitas warna suara yang dihasilkan sewaktu kita bermain oboe, warna suara yang indah merupakan aset terbesar bagi setiap pemain oboe yang didukung pastinya oleh warna suara reed nya juga.. Jadi kita harus selalu dengarkan baikbaik suara yang kita hasilkan dan, karena keinginan untuk membuat bunyi yang indah merupakan hal yang penting pada saat kita menghasilkan bunyi tersebut. Ada beberapa faktor penyebab warna suara yang buruk yang dialami pemain oboe, yaitu:

\section{a. Kesalahan dalam mengatur nafas}

Kesalahan mengontrol volume aliran udara bisa berakibat nada menjadi tidak bulat, dan tidak stabil. Apabila kita tidak cukup mengambil nafas, atau tidak cukup tinggi tekanan udaranya, akan menghasilkan suara yang mati atau tidak ada resonansinya. Dan apabila kita mengeluarkan terlalu banyak udara melalui reed, maka akan menghasilkan suara yang kasar dan tidak terkontrol, atau biasa disebut overblowing, dan akan timbul bunyi yang tidak diinginkan pada beberapa nada. Terlalu sedikit udara yang digunakan untuk membuat reed bergetar dengan semestinya, tidak akan sesuai dengan instrument. Nada yang dihasilkan menjadi tipis dan 
tidak teratur, dan bahkan tidak berbunyi sama sekal dibeberapa nada.

\section{b. Warna suara yang tidak bagus}

Ini disebabkan oleh kesalahan dalam pengontrolan ambassir, biasanya dikarenakan bibir atas atau bawah (atau mungkin keduanya) yang mencengkeram terlalu kuat, bisa juga karena rahang atas atau bawah yang terlalu menonjol, gigi atas dan bawah tidak cukup terpisah, dan otot sekitar mulut yang terkontraksi dengan erat atau terlalu longgar. Seberapa bagian reed yang tepat yang tertutup oleh bibir biasanya bervariasi tergantung dari pemain itu sendiri atau bentuk fisiknya, reed yang digunakan, dan lainlain. Kita akan bisa merasakannya, setelah mendengarkan dengan teliti suara yang dihasilkan di awal. Ada hal yang perlu diingat, bahwa, jika reed masuk terlalu dalam ke dalam mulut maka akan menghasilkan nada yang keras, kasar, tebal, dan pitch cenderung menjadi ketinggian. Sebaliknya, jika terlalu sedikit bagian reed yang masuk ke dalam mulut maka bunyi yang dihasilkan akan kecil, tipis dan pitch akan cenderung kurang naik khususnya di nada-nada register atas.

c. Reed yang tidak bagus dan tidak sesuai dengan ambassir kita

Reed sangat berpengaruh terhadap kualitas nada yang dihasilkan. Nada dan intonasi yang terkontrol dengan baik merupakan aset yang lebih besar daripada kemampuan memainkan staccato yang sangat cepat atau jari yang mampu bergerak dengan cepat. Intinya, seorang pemain profesional harus memiliki seluruh kualifikasi tersebut. Tapi bagi pemula, sebaiknya menguasai cara memainkan nada-nada dengan tempo pelan dengan indah. Ketika berlatih, jangan menghindari masalah pada instrumen, sebelum kita dapat menguasai cara mengontrolnya dengan tepat.

Perbedaan warna suara dari nada nada yang dihasilkan instrumen oboe dapat dilakukan. Pada dasarnya tiap instrumen memiliki perbedaan warna dari setiap nada yang dihasilkan. Pada instrumen oboe terdapat 3 jenis warna dari register nada yang berbeda:

1) Nada paling rendah bes1 sampai nada f1 ' itu berkarakter tebal dan kuat

2) Nada g1 ke a2" itu tajam dan menonjol

3) Nada b2 smp nada e3 itu tipis terang

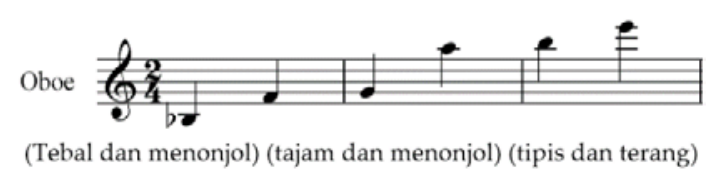

Ilustrasi 12.

Register Oboe dan Karakter Warna Suaranya

\section{Tounging}

Tounging atau kontrol lidah adalah salah salah satu indera yang berpengaruh untuk insrument tiup kayu khusunya oboe, dan harus selalu digunakan ketika memulai frase untuk memulai getaran reed, dan juga untuk penekanan aliran udara untuk menghasilkan suara yang terpisah dengan panjang yang bervariasi. Ketika anda secara normal mengucapkan 'Ter' ujung lidah akan menyentuh langit-langit mulut tepat di atas gigi anda dan segera akan menjauh lagi. Hal yang sama terjadi ketika anda mengucapkan 'Ter' dengan oboe, ujung lidah anda akan menyentuh ujung reed dan ujung lidah itu segera menjauh lagi.

Teknik ini harus dilakukan dengan lembut dalam suatu bagian yang terpisah, itu hanyalah untuk menekan aliran udara dengan menghentikan getaran reed selama sepersekian detik. Cobalah untuk merasakan seolah-olah aliran udara yang mengalir di dalam oboe secara terus menerus sementara anda bermain sebuah phase yang terpisah, bayangkanlah suatu bagian sebagai satu garis legato daripada sekelompok nada yang terpisah. Ketika tidak menggunakan lidah, lidah harus tetap dalam kondisi rileks 
sedekat mungkin dengan reed tanpa menyentuhnya.

Penggunaan lidah sangat dibutuhkan untuk teknik staccato. Panjang nada yang terpisah pada teknik staccato dapat divariasikan dengan pengucapan konsonan oleh lidah pada reed. Ter akan menghasilkan bunyi yang pendek dan Der menghasilkan suara yang lebih panjang dan lembut, dan seluruh variasi dalam panjang nada yang terpisah dan tekanannya bisa didapatkan dengan mengucapkan bunyi Ter dan Der yang sedikit berbeda tergantung kebutuhan (tekanan yang halus dan lembut, atau melodis) nada yang terpisah dapat dibuat dengan lidah yang sedikit rileks, menyentuh reed dengan gerakan membelai: tapi metode ini tidak ditekankan sampai kontrol embouchure yang baik telah dicapai.

Lidah tidak boleh kencang atau kaku, seberapapun pendeknya staccato. Pada umumnya pemain pemula mungkin akan merasa bahwa gerakan lidah ini akan mengganggu ambassir dan mungkin membuka bibir dari permukaan gigi, yang mengakibatkan udara bocor di sekeliling reed, Dan kita mengencangkan ambassir dalam usaha untuk mengontrolnya.

Ketika gerakan lidah ini dirasa sudah cukup baik, maka ambassir yang terlampau tertutup rapat tidak diperlukan lagi karena gerakan lidah yang benar, dan sesungguhnya tidak mengganggu Ambassir. Apabila sudah bisa dikuasai, cobalah membuat Ambassir lebih rileks, begitu juga dengan lidah, ketika sedang berlatih tonguing, untuk menetralkan kecenderungan yang mengakibatkan ambassir menjadi tidak rileks. Untuk itu mulailah melatih lidah tanpa menggerakkan jari dengan memainkan sebuah nada, pertama dalam register yang mudah dan dilanjutkan ke register yang tinggi dalam instrument tersebut, menekan suara dengan lidah. Mulailah dengan mengatakan Ter beberapa kali, lalu Der, kemudian variasikan panjangnya untuk membuat tipe nada terpisah yang berbeda- beda. Kemudian memainkan tangga nada dengan tempo tetap, perlahan pada awalnya, setelah itu diulangi masing-masing nada dua kali, tiga kali, empat kali dan seterusnya. Sedikit demi sedikit naikkan tempo agar otot lidah dan dan jari-jari bisa menyesuaikan diri dan bekerja sama dengan baik yang menggunakan panjang staccato yang berbeda-beda. Kemudian latihan tangga nada dengan interval yang berbeda-beda.

Teknik Tounging ini dibagi menjadi tiga, yaitu single tounging, double, dan triple tounging. Tetapi di Konserto mozart hanya menggunakan single dan double tounging saja. Dobel dihasilkan dari pengucapan 2 konsonan secara bergantian ter dan ker, Ter adalah cara yang biasa dengan lidah di reed, dan Ker hanya ketika diucapkan. Metode ini efektif untuk diterapkan pada beberapa instrumen tiup kayu, terutama flute, tapi kurang berhasil jika diterapkan pada oboe karena sulitnya menghasilkan suara Ker dengan sebersih dan sejelas Ter, terutama ketika memainkan interval yang lebih lebar. Sulit juga mengontrol kecepatan tonguing dobel pada oboe.

Ada beberapa teknik Single tounging yang terdapat pada Konserto Mozart ini, terdapat pada birama 32, 65, 66 di ketukan ke-3:

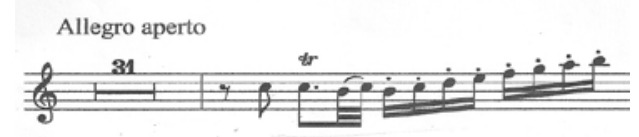

Ilustrasi 13.

Dimainkan dengan single tounging

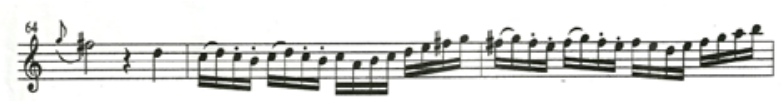

Ilustrasi 14.

Dimainkan dengan single tounging

Ada juga beberapa teknik double tounging yang terdapat pada Konserto Mozart ini, salah satunya pada pada birama 83 , dan 132:

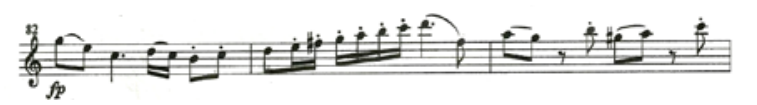

Ilustrasi 15.

Dimaikan dengan double tounging 


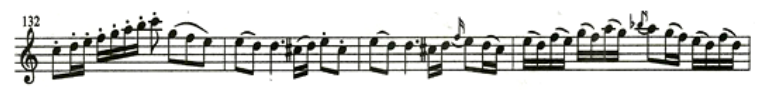

Ilustrasi 16.

Dimaikan dengan double tounging

Pada birama 83, dan 132, ada juga pemain yang menggunakan teknik single tounging, tetapi lebih banyak menggunakan double tounging pada bagian itu.

Pemain yang sudah profesional mungkin bisa berhasil melakukannya, namun bagi pemula disarankan untuk berlatih meningkatkan kecepatan single tonguing terlebih dahulu, dan mulai berlatih dobel ketika pengontrolan single tonguing sudah dapat dilakukan dengan baik.

\section{Frasering dan Artikulasi}

Karya Konserto C mayor Mozart ini adalah salah satu karya yang terkenal untuk instumen oboe. Konserto Mozart mem-punyai ciri khas tersendiri yaitu banyak menggunakan teknik staccato dan Legato, gabungan kedua nya, serta mempunyai karakter yang tajam lincah dan ringan. Frasering, yaitu pengaturan kejelasan penyajian frase-frase melodi pada karya ini tidak semata-mata didasarkan atas pemaha-man hasil analisis bentuk musik namun juga penggarapan artikulasi penegasan teknikteknik staccato, legato, dan nada-nada hias semisal appogiatura secara akurat.

\section{a. Legato}

Legato adalah teknik memainkan not dalam satu rangkaian atau frase tanpa jeda apapun serta diantara not- not tersebut dan perpindahan not ke not berlangsung dengan rapat atau menyambung. Teknik legato dapat dilatih dengan cara latian seperti di bawah ini:

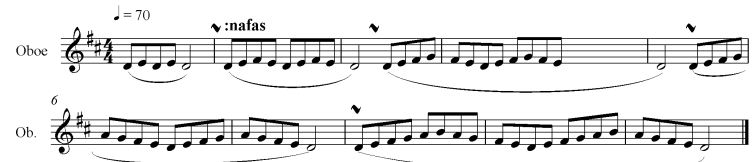

Ilustrasi 17.

Bagian-bagian legato
Setelah melakukan latian diatas, lanjutkan ke nada yang selanjutnya dengan pola yang sama. Latian ini juga sekaligus membantu kita dalam memainkan dan sebuah frasering pada lagu. Legato pada lagu Konserto C mayor Mozart bagian I, ada dua macam yaitu:

1) Tanda Legato yang berfungsi memperpanjang harga nada tersebut terdapat dua nada yang sama atau lebih (Legatura), Contohnya pada birama 33 sampai 36:

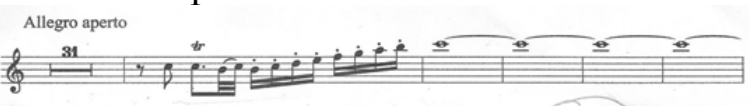

\section{Ilustrasi 18.}

Legato untuk memperpanjang durasi sebuah nada.

2) Tanda Legato yang cara memainkannya disambung tanpa memutus nada, biasanya legato tersebut menandai dua nada atau lebih yang berlainan. Contoh pada birama 68, 69, 70 ketukan 1 dan 4 , dan birama 147:

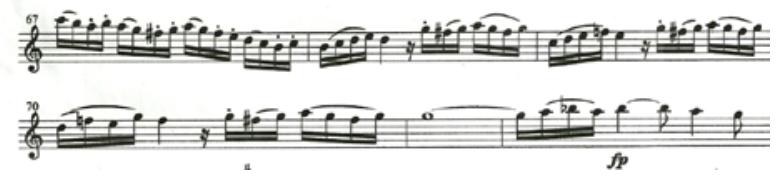

Ilustrasi 19.

Legato untuk menghasilkan dua nada atau lebih secara bersambung

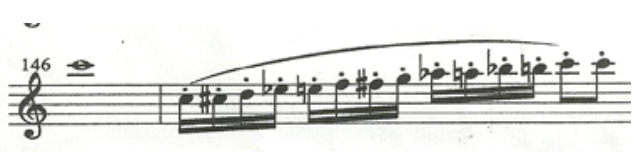

Ilustrasi 20.

Legato sebagai tanda kesatuan sekelompok nada-nada

\section{b. Staccato}

Staccato adalah teknik yang dimainkan dengan cara pendek-pendek pada setiap not. Ditandai dengan satu titik diatas atau dibawah sebuah not yang akan dimainkan 
Cara berlatih staccato pada instrumen oboe adalah sebagai berikut:

- Sebelum memulai staccato, kita harus mempersiapkan dan menguatkan ambasir dengan latian nada panjang.

- Gunakan metronom untuk membantu menjaga tempo

- Memainkan nada D1 dengan ritmis $1 / 4$ kurang lebih dalam tempo $=70$. (karena nada D1 nada yang gampang untuk dibunyikan)

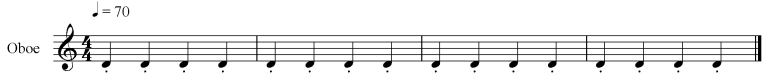

Ilustrasi 21.

Latihan staccato pada nada seperempat

- Bila sudah terasa nyaman kecepatan lidah mulai ditambah dengan ritmis seperdelapan.

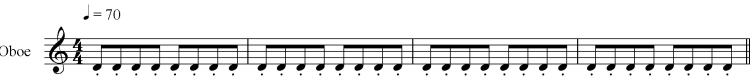

Ilustrasi 22.

Latihan staccato pada nada nada seperdelapan

- Bila kedua tahap ini sudah dilalui dengan baik, kemudian dimbah menjadi ritmis seperenambelas.

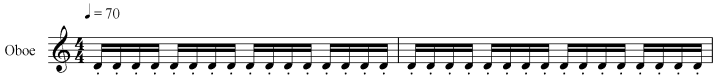

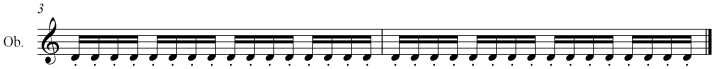

Ilustrasi 23.

Latihan staccato pada nada seperenambelas.

- Memainkan tangga nada C mayor 1 oktaf dalam tempo yang sama dengan ritmis seperempat, seperdelapan, dan seperenambelas, dan dapat dikembangkan ke tangga nada yang lain.

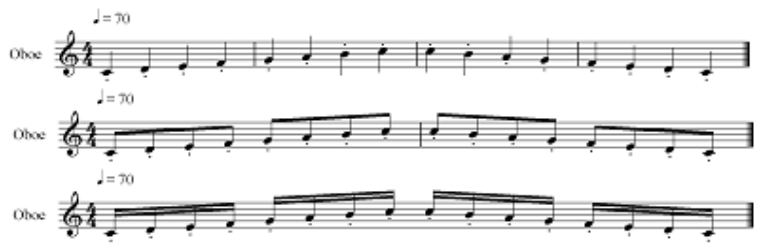

Ilustrasi 24.

Tahapan latihan staccato pada tangga nada.
- Bila dalam tempo tersebut sudah terasa nyaman, tempo dapat dinaikan lagi kurang lebih menjadi tempo $=90$ dalam not seperempat, dan dengan memainkan tangga nada dengan pengolahan ritmis yang masih sama, bisa juga dengan penggabungan pola ritmis.

- Tempo masih memungkinkan dapat ditingkatkan lagi sampai titik dimana pemain dapat menjaga tempo dengan stabil

- Latihan teknik staccato harus dilatih secara rutin dengan menjaga kestabilan ambasir dan lidah. Bila ambasir dan lidah sudah terasa lelah dianjurkan istirahat duludan jangan diforsir.

Staccato dalam lagu Konserto C mayor mozart bagian I terdapat pada birama 32 di nada seperenambelasan, birama 50, 53, 56 di nada seperdelapan.

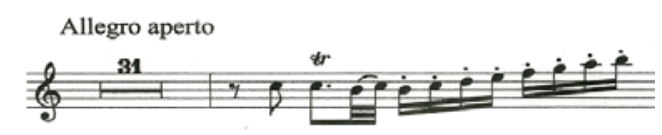

Ilustrasi 25.

Penerapan staccato pada Konserto C mayor Mozart.

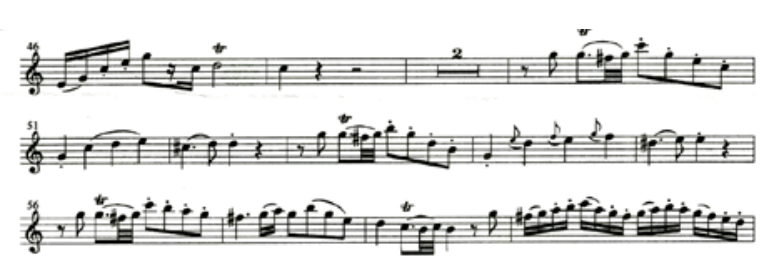

Ilustrasi 26.

Penerapan staccato pada Konserto $C$ mayor Mozart.

\section{c. Appogiatura}

Appogiatura yaitu nada-nada kecil yang terdapat di depan atau sebelum nadanada pokok, biasanya disebut dengan nada hias. Appogiatura ini terdapat pada birama 51, 128, 129, 130, 134 di ketukan 4, dan 135 di ketukan 3 


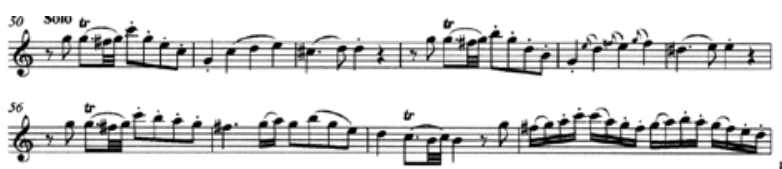

Ilustrasi 27.

Penerapan nada-nada appogiatura.

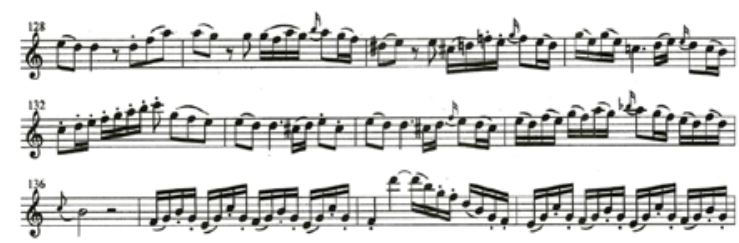

Ilustrasi 28.

Penerapan nada-nada appogiatura.

\section{Kontribusi Teknis terhadap Interpretasi Penyajian}

Pengetahuan bentuk musik dan penguasaan teknik-teknik oboe seperti per-napasan, ambasir, dinamik, tounging, dan intonasi, akan memberikan kontribusi yang besar terhadap interpretasi penyajian karya ini. Tanpa landasan teknik-teknik tersebut maka akan sulit untuk mencapai artikulasi yang jelas dalam penyajian bagian-bagian staccato, legato, dan juga nada-nada hias, khususnya appogiatura.

Untuk memainkan teknik permainan pada Konserto ini membutuhkan kecepatan lidah dan kecepatan jari secara bersamaan, dan interval yang berbeda-beda. Berikut ini adalah bagian yang termasuk sulit memainkannya dan solusi untuk mengatasinya, yaitu dapat dilatih dengan latihan dari tempo yang lambat (70) sampai tempo yang diinginkan, dengan menggunakan metronom seperti di bawah ini:

Bagian sulit yang terdapat di Konserto C mayor Mozart Bagian I pada birama 43:

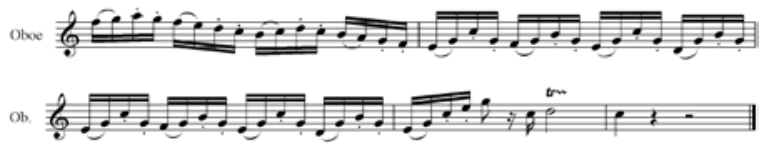

Ilustrasi 29.

Bagian-bagian artikulasi yang sulit
Bagian ini dapat dilatih dengan latian tangga nada $\mathrm{C}$ major satu oktaf dengan artikulasi dua staccato dan dua legato seperti dibawah ini:

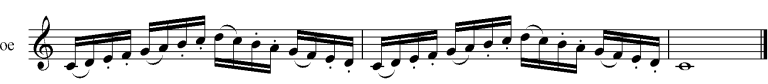

Ilustrasi 30:

Latihan artikulasi melalui tangga nada

Setelah itu dilanjutkan dengan latihan tangga nada berjarak satu terts:

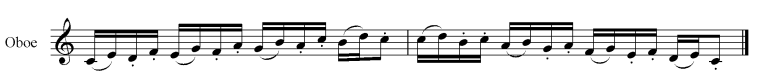

Ilustrasi 31.

Tangga nada dalam interval ters melodik.

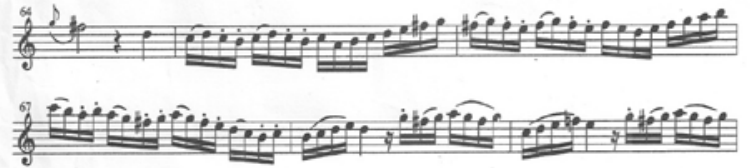

Ilustrasi 32.

birama $65-67$

Pada birama ini agak sulit dimainkan karena register nada mencapai nada $\mathrm{c} 2$, di dalam tangga nada g mayor, untuk memudahkannya bagian ini dilatih dengan cara latihan seperti dibawah ini:

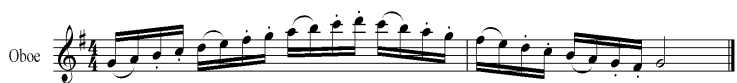

Ilustrasi 33.

Latihan tangga nada

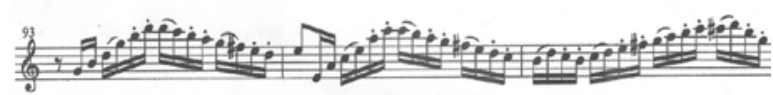

Ilustrasi 34.

birama $93-95$

Birama ini sulit dimainkan karena ada interval yang berjarak terts kuint dan oktaf, untuk bagian ini dapat dilatih dengan cara di bawah ini:

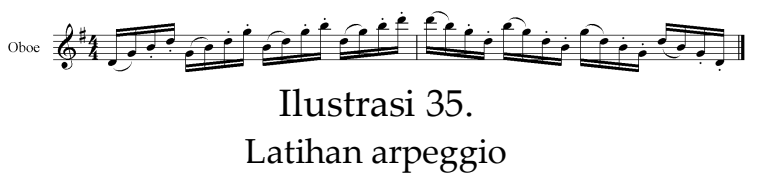


Dan dilengkapi dengan latihan dibawah ini:

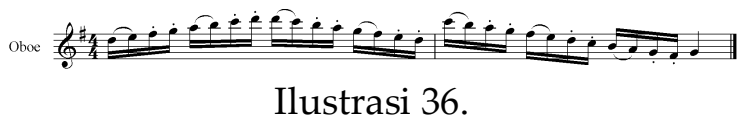

Latihan bagian tangga nada

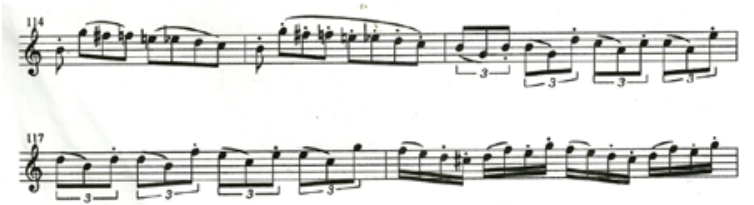

Ilustrasi 37.

birama $116-117$

Pada birama ini memiliki posisi yang sulit, karena ada nada triol berjarak interval yang berbeda-beda dengan penjarian yang agak jarang digunakan, untuk itu bagian ini dilatih dengan cara latihan seperti dibawah ini:
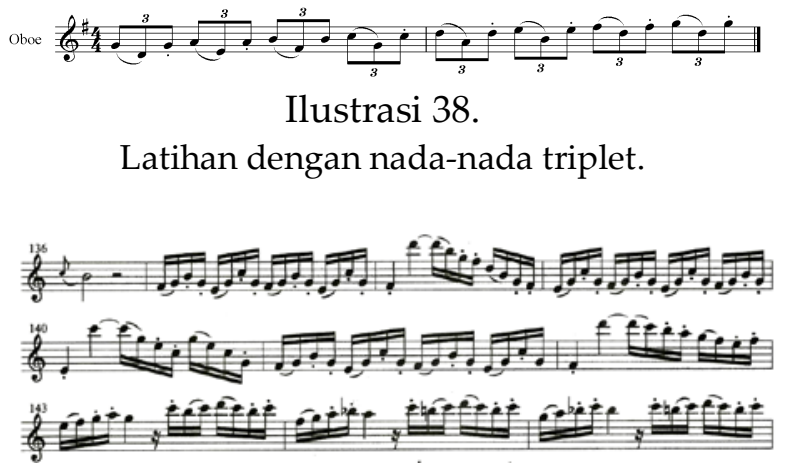

Ilustrasi 39.

birama $137-145$

Pada birama ini terdapat teknik yang sangat sulit dalam Lagu Konserto Mozart bagian I, karena terdapat interval yang sulit dan berjarak lebih dari satu oktaf, dan memiliki register nada yang tinggi, untuk itu sangat diperlukan latihan seperti dibawah ini:

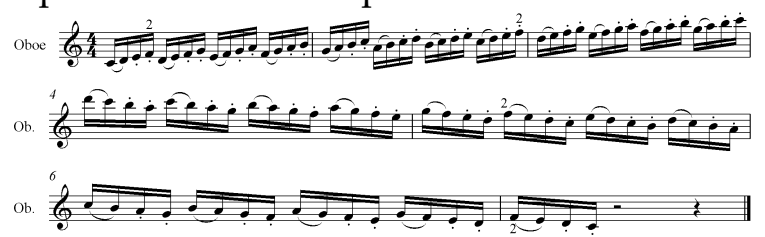

Ilustrasi 38.

Latihan motif-motif sikuen naik dan turun

Untuk latihan diatas pada nada $\mathrm{f}$ yang ada angka 2 nya, berarti menggunakan posisi alternatif, karena setelah nada f memudahkan kita ke nada d. Apabila kita menggunakan posisi $\mathrm{f}$ biasa, akan sulit pindah ke nada d.

Dari latihan yang telah dibahas diatas, jangan pernah melupakan teknik dasar (basic), yaitu sebelum latihan, kita harus latihan nada panjang dari nada yang paling rendah ke nada yang paling tinggi apabila kita tidak latihan nada panjang terlebih dahulu, maka hasil yang di dapatkan akan kurang maksimal.

\section{Penutup}

Konserto C Mayor karya Wolfgang Amadeus Mozart bagian pertama merupakan salah satu materi ujian mayor di jurusan musik. Dalam konserto bagian I ini terdapat beberapa teknik mulai dari teknik pernapasan, ambassir, intonasi dan dinamik, kualitas nada (Tone Quality), kontrol lidah, serta frasering dan artikulasi. Semuanya sangat berpengaruh, untuk bisa memainkan Konserto ini dengan baik dan benar. Awali dengan latihan nada panjang sebelum kita latihan yang lain, supaya hasil yang kita inginkan maksimal.

Konserto Oboe ini Memiliki tingkat kesulitan tinggi di birama 43,65, 93, 116, dan137, karena dimainkan dengan tempo yang cepat, sehingga warna suara dan intonasi yang dihasilkan kurang maksimal. Namun hal ini dapat diatasi dengan syarat pemain telah mempelajari dan menguasai teknik- teknik yang sudah dibahas pada bab III. Dengan demikian, penguasaan teknik sangat dibutuhkan oleh semua pemain khususnya pemain oboe dalam mempelajari Konserto Mozart ini.

Secara umum Konserto C mayor oboe ini bentuknya sonata allegro yang dimodifikasi yang terbagi menjadi tiga bagian yaitu (eksposisi tema I dan tema II) pengembangan tema (development) dan rekapitulasi. Sebagaimana bentuk Konserto zaman klasik pada umumnya adalah bentuk sonata dengan dua eksposisi (yang pertama dimain- 
kan oleh orkestra (piano) dan yang kedua dimainkan oleh solo dan orkestra (piano) sebagai kontrasnya.

\section{Referensi}

Banoe, Pono. 2003. Kamus Musik, Cetakan 1. Yogyakarta: Kanisius.

Goosens, Leon \& Roxburgh, Edwin. 1977. Yehudi Menuhin Music Guide Oboe. London: Macdonal \& Jane's Publisher.

Gay, Peter. 2005. Mozart Simfoni Hidup Sang Maestro. Yogyakarta: Bentang.

Huching, Arthur. 1980. "Concerto" dalam Sadie, Stanley (ed) The New Groove
Dictionary of Music and Musician. Vol. 4. London: Macmilian Publisher Limited.

Mc Neill, Rhoderick J. 1998. Sejarah musik 2, Cetakan 2. Jakarta: Gunung Mulia, Philip, Bate. 1962. The Oboe and Outline of Its History and Development. New York: Philosopical Library.inc

Rothwell, Evelyn. 1982. Oboe Technique. Third edition. Great Britain: University press,

Saucier, Gene. A. 1981. Woodwinds: Fundamental Performance Technique. New York: Macmillan Publishing Co. 